\title{
Mobile Phone Use in Psychiatry Residents in the United States: Multisite Cross-Sectional Survey Study
}

Shih Gipson ${ }^{1,2}$, MD; John Torous ${ }^{2,3}$, MD; Robert Boland ${ }^{2,4}$, MD; Erich Conrad ${ }^{5}$, MD

\author{
${ }^{1}$ Department of Psychiatry, Boston Children's Hospital, Boston, MA, United States \\ ${ }^{2}$ Department of Psychiatry, Harvard Medical School, Boston, MA, United States \\ ${ }^{3}$ Department of Psychiatry, Beth Israel Deaconess Medical Center, Boston, MA, United States \\ ${ }^{4}$ Department of Psychiatry, Brigham and Women's Hospital, Boston, MA, United States \\ ${ }^{5}$ Department of Psychiatry, Louisiana State University Health Sciences Center, New Orleans, LA, United States
}

\section{Corresponding Author:}

Shih Gipson, MD

Boston Children's Hospital

Department of Psychiatry

300 Longwood Ave

Boston, MA, 02115

United States

Phone: 16173556680

Fax: 16177300319

Email: mariegipsonmd@gmail.com

\section{Abstract}

Background: Mobile technology ownership in the general US population and medical professionals is increasing, leading to increased use in clinical settings. However, data on use of mobile technology by psychiatry residents remain unclear.

Objective: In this study, our aim was to provide data on how psychiatric residents use mobile phones in their clinical education as well as barriers relating to technology use.

Methods: An anonymous, multisite survey was given to psychiatry residents in 2 regions in the United States, including New Orleans and Boston, to understand their technology use.

Results: All participants owned mobile phones, and 79\% (54/68) used them to access patient information. The majority do not use mobile phones to implement pharmacotherapy $(62 \%, 42 / 68)$ or psychotherapy plans $(90 \%, 61 / 68)$. The top 3 barriers to using mobile technology in clinical care were privacy concerns $(56 \%, 38 / 68)$, lack of clinical guidance $(40 \%, 27 / 68)$, and lack of evidence $(29 \%, 20 / 68)$.

Conclusions: We conclude that developing a technology curriculum and engaging in research could address these barriers to using mobile phones in clinical practice.

(JMIR Mhealth Uhealth 2017;5(11):e160) doi: 10.2196/mhealth.7146

\section{KEYWORDS}

technology; graduate medical education; mobile phone; psychiatry

\section{Introduction}

Mobile technology ownership is common in the United States with $77 \%$ of the population owning a mobile phone [1]. In learning and in practice, medical students and trainees also have adopted using mobile devices. However, little is known about how psychiatry residents use mobile technology, particularly mobile phones, in their training. The current data on how medical trainees use mobile devices as a part of their education are limited. A study from Canada has found that medical students receive instructions on searching and assessing primary medical literature, but few receive formal instruction on non-traditional tools such as general use search engines, Wikipedia, or social media [2]. The authors suggest that teaching about nontraditional sources may enhance the current curriculum. This was underscored by another survey of 62 psychiatry residents which showed that $68 \%$ primarily use online resources for education rather than printed materials [3]. Given that majority of the population use mobile apps to access digital media, it seems likely that medical students and residents also 
access clinical resources via their phones and apps [4]. However, it is unclear how residents and fellows in psychiatry use their mobile devices as a clinical resource. In 2014, Boruff et al [5] conducted a study to understand how Canadian medical students, residents, and faculty utilized their mobile phones to answer clinical questions and medical information. They found that mobile phones and tablets were broadly used in clinical settings and medical students were more likely to use these technologies. This is not a surprising finding due to the convenience and efficiency of mobile devices when retrieving information from the Internet. In a 2016 study, Gagnon et al [6] performed a systematic review of available literature to understand factors that influenced health care professionals in adapting mobile devices in their practice. They found that perceived usefulness and ease of use were some of the major factors in adapting mobile technologies among clinicians.

Although residents and fellows (trainees) are taught about protecting patient information in electronic medical records (EMRs), mobile technologies present new challenges that are distinct from those related to EMRs. Mobile devices like smartphones can be used interchangeably for professional and personal use including looking up patient information, sharing a photo on social media, and searching clinical decision support information. The use of these devices presents a new challenge to clinicians in integrating mobile phones in clinical use. These challenges include boundary issues as well as maintaining patient data safety. Although younger generations of psychiatry residents and fellows may often be considered tech savvy, their mobile phone use in clinical settings remains unclear.

To date, the most comprehensive data on mobile phone use in clinical practice are from a broad survey of physicians and nurses in the United Kingdom and psychiatry-specific data have not been reported [7]. Thus, in this study, we aim to provide an understanding on how psychiatric residents and fellows are using mobile phones in their clinical education and what barriers they perceive to this use.

\section{Methods}

To understand how psychiatry residents and fellows use mobile technology in clinical practice, we performed a multisite survey in 2 psychiatry residency programs in different regions of the United States, which included Louisiana State University Health Sciences Center New Orleans, Louisiana, and Longwood psychiatry residency in Boston, Massachusetts. These surveys were approved by the institutional review board of each site, and the surveys were conducted anonymously and voluntarily. No compensation was provided to participate in the survey.

Paper surveys were provided to psychiatry trainees during grand rounds for a 4-week period. Surveys in New Orleans, Louisiana, were collected in May-June 2015, and then collected in Boston, Massachusetts, in November 2015. An electronic version of the survey on RedCap was available in New Orleans, Louisiana. There were a total of 26 questions on this survey, developed by the authors, which inquired about their mobile technology use in administrative tasks, communication, and treatment planning. Participants were also provided with text boxes to elaborate on apps they used in administrative tasks, communication, and treatment planning. We also surveyed residents on the possible barriers in implementing mobile technology in clinical practice through multiple choice as well as an option to write in barriers that were not included in the available choices. Barriers provided were based on a previous study that identified barriers in using electronic resources among medical students on their psychiatry clerkship [3]. The survey questions have been listed in Table 1. The completed surveys were subsequently entered and analyzed using Microsoft Excel on an encrypted and password-protected computer.

\section{Results}

In New Orleans, 25 out of 41 trainees participated in this survey, and in Boston, 43 out of 52 trainees participated, which gave a total of 68 participants.

All the 68 participants owned a mobile phone or tablet. Moreover, $22(32 \%)$ trainees practiced mostly in an outpatient setting and $41(60 \%)$ practiced mostly in an inpatient setting. In addition, $5(7 \%)$ trainees reported that they practice in a setting other than inpatient and outpatient psychiatry. A total of $54(79 \%)$ of our participants reported that they use a mobile device to access protected patient information. Furthermore, 13 (19\%) participants reported that they did not use a mobile device to access protected patient information, and $1(1 \%)$ trainee did not respond to this question. Of the participants, 29 (43\%) trainees reported using mental health-related apps to access protected patient information on their mobile device. Moreover, $40(59 \%)$ trainees reported using an Internet site to access protected patient information.

A total of $16(24 \%)$ trainees reported using a mobile device to communicate with patients, and $38(56 \%)$ trainees reported that they did not use a mobile device to communicate with patients. Moreover, 14 (21\%) participants did not respond when asked whether they used a mobile device to communicate with patients, and $38(56 \%)$ trainees reported using a desktop computer to communicate with patients. Furthermore, 28 (41\%) residents and fellows reported that they did not use a desktop computer to communicate with patients, and2 (3\%) participants did not respond to this question. In addition, $26(38 \%)$ trainees used a mobile device when implementing medication regimens, and $42(62 \%)$ trainees did not use a mobile device when implementing medication regimens. A total of 16 (24\%) participants reported using apps to implement medication regimens, and 15 (22\%) trainees reported using an Internet site to implement medication regimens. Only $6(9 \%)$ trainees reported using a mobile device to implement psychotherapy plans, and $61(90 \%)$ trainees did not use a mobile device when implementing psychotherapy plans. Moreover, $1(1 \%)$ trainee did not respond to this question. A total of $3(4 \%)$ trainees used apps, and $2(3 \%)$ trainees used Internet sites to implement psychotherapy plans.

Furthermore, $30(44.1 \%)$ trainees used a mobile device to manage their clinic schedule; $38(56 \%)$ trainees did not use a mobile device to manage their clinic schedule; 30 (44\%) trainees intended to use a mobile device to manage their clinic schedule; and $38(56 \%)$ trainees did not intend to use a mobile device to manage their clinic schedule. 
Table 1. Survey questions.

\begin{tabular}{|c|c|}
\hline Survey questions & Answer choices \\
\hline How many years old are you? & years old \\
\hline \multirow[t]{4}{*}{ Which one of the following genders do you most closely identify? } & Male \\
\hline & Female \\
\hline & Transgender \\
\hline & Prefer not to specify \\
\hline \multirow[t]{4}{*}{ Which one label do you most closely identify? } & Attending physician \\
\hline & Resident physician \\
\hline & Medical student \\
\hline & Other (please specify): \\
\hline \multirow[t]{3}{*}{ In which one practice setting do you spend most of your clinical hours? } & Outpatient \\
\hline & Inpatient \\
\hline & Other \\
\hline \multirow[t]{2}{*}{ Do you own a smartphone or tablet? } & Yes \\
\hline & No \\
\hline \multirow[t]{2}{*}{ Do you intend to purchase a smartphone or tablet in the next 6 months? } & Yes \\
\hline & No \\
\hline \multirow{2}{*}{$\begin{array}{l}\text { Do you use a mobile device (such as smartphone or tablet) to access protected patient information, such as their } \\
\text { chart or their e-mail messages to you? }\end{array}$} & Yes \\
\hline & No \\
\hline \multirow[t]{3}{*}{ Which methods do you use to access protected patient information on your mobile device? (Check all that apply) } & Apps \\
\hline & Internet Sites \\
\hline & Other \\
\hline \multirow{2}{*}{$\begin{array}{l}\text { Do you intend to use a mobile device to access protected patient information, such as their chart or their e-mail } \\
\text { messages to you? }\end{array}$} & Yes \\
\hline & No \\
\hline \multirow[t]{2}{*}{ Do you use a mobile device to communicate with patients? } & Yes \\
\hline & No \\
\hline \multirow[t]{2}{*}{ Do you use a desktop computer to communicate with patients? } & Yes \\
\hline & No \\
\hline \multirow[t]{2}{*}{ Do you use a mobile device when implementing medication regimens? } & Yes \\
\hline & No \\
\hline \multirow[t]{3}{*}{ Which methods do you use to implement medication regimens for your patient? (Check all that apply) } & Apps \\
\hline & Internet Sites \\
\hline & Other \\
\hline \multirow[t]{2}{*}{ Do you use a mobile device when implementing psychotherapy plans? } & Yes \\
\hline & No \\
\hline \multirow[t]{3}{*}{ Which methods do you use to implement psychotherapy regimens for your patient? (Check all that apply) } & Apps \\
\hline & Internet Sites \\
\hline & Other \\
\hline \multirow[t]{2}{*}{ Do you use a mobile device to manage your clinic schedule? } & Yes \\
\hline & No \\
\hline \multirow[t]{2}{*}{ Do you intend to use a mobile device to manage your clinic schedule? } & Yes \\
\hline & No \\
\hline
\end{tabular}




\begin{tabular}{|c|c|}
\hline Survey questions & Answer choices \\
\hline \multirow[t]{2}{*}{ Do you use a mobile device to communicate with other staff? } & Yes \\
\hline & No \\
\hline \multirow[t]{5}{*}{ Which modality do you communicate with your mobile device? (Check all that apply) } & Email \\
\hline & Instant Messaging \\
\hline & Text Messaging \\
\hline & Call \\
\hline & Other \\
\hline \multirow{2}{*}{$\begin{array}{l}\text { In the last } 3 \text { months, have you recommended patients to use supplemental apps to their current medication } \\
\text { management? }\end{array}$} & Yes \\
\hline & No \\
\hline Why or why not? & Text box \\
\hline \multirow{2}{*}{$\begin{array}{l}\text { In the last } 3 \text { months, have you recommended patients to use supplemental apps to their current psychotherapy } \\
\text { plan? }\end{array}$} & Yes \\
\hline & No \\
\hline Why or why not? & Text box \\
\hline \multirow[t]{2}{*}{ In the last 3 months, have you recommended online resources to patients? } & Yes \\
\hline & No \\
\hline Why or why not? & Text box \\
\hline \multirow[t]{8}{*}{ What do you feel are the greatest barriers for using mobile devices in the care of patients? (Select up to three) } & Privacy \\
\hline & Safety \\
\hline & Liability \\
\hline & Cost \\
\hline & Too much data \\
\hline & Lack of evidence \\
\hline & Lack of reimbursement \\
\hline & Lack of clinical guidance \\
\hline
\end{tabular}

A total of $61(90 \%)$ trainees used a mobile device to communicate with clinic staff and only $6(9 \%)$ trainees did not. Moreover, $1(1 \%)$ trainee did not answer this question. When asked about the modality used to communicate with clinic staff, $56(84 \%)$ trainees reported using email, $10(15 \%)$ trainees reported using an instant messaging app, 44 (66\%) trainees reported using text, and $43(64 \%)$ trainees reported calling clinic staff with their mobile devices.

In the last 3 months of completing the survey, 18 (27\%) trainees reported recommending supplemental apps to patients in their current medication management, $48(71 \%)$ trainees reported they do not, and $2(3 \%)$ trainees did not respond to this question. Moreover, 19 (28\%) trainees recommended supplemental apps to patients in their current psychotherapy plan, 48 (71\%) trainees did not recommend any supplemental apps, and $1(1 \%)$ trainee did not respond to this question. In the last 3 months of completing the survey, $38(56 \%)$ trainees recommended online resources to patients, $27(40 \%)$ trainees did not recommend online resources, and $3(4 \%)$ trainees did not respond to this question.

When surveyed on perceived greatest barriers for using mobile devices in the care of patients, $38(56 \%)$ trainees selected privacy, 27 (40\%) trainees selected lack of clinical guidance, $20(29 \%)$ trainees selected lack of evidence, $15(22 \%)$ trainees selected liability, $12(18 \%)$ trainees selected too much data, 11 (16\%) trainees selected lack of reimbursement, $5(7 \%)$ trainees selected cost, and $5(7 \%)$ trainees selected safety.

Although the authors included questions on gender and age, there were a limited number of responses between both programs, and these questions were omitted in this study. Participants were provided with textboxes for various questions as listed in Table 1, but there were limited number of responses and they were omitted in this study. The above-described data are also provided in Tables 2 and 3. 
Table 2. Survey responses.

\begin{tabular}{|c|c|}
\hline Combined survey questions & $\mathrm{n}(\%)$ \\
\hline \multicolumn{2}{|c|}{ In which one practice setting do you spend most of your clinical hours? } \\
\hline Outpatient & $22(32.35)$ \\
\hline Inpatient & $41(60.3)$ \\
\hline Other & $5(7.4)$ \\
\hline \multicolumn{2}{|c|}{ Do you own a smartphone or tablet? } \\
\hline Yes & $68(100)$ \\
\hline No & $0(0)$ \\
\hline \multicolumn{2}{|c|}{$\begin{array}{l}\text { Do you use a mobile device (such as a smartphone or tablet) to access protected patient information, such as their } \\
\text { chart or their email messages to you? }\end{array}$} \\
\hline Yes & $54(79.41)$ \\
\hline No & $13(19.1)$ \\
\hline Did not answer & $1(1.5)$ \\
\hline \multicolumn{2}{|c|}{ Which modality do you communicate with your mobile device? } \\
\hline Email & $56(83.5)$ \\
\hline Instant messaging app & $10(14.9)$ \\
\hline Text & $44(65.7)$ \\
\hline Call & $43(64.2)$ \\
\hline \multicolumn{2}{|c|}{ In the last 3 months, have you recommended patients to use supplemental apps to their current medication management? } \\
\hline Yes & $18(26.5)$ \\
\hline No & $48(70.6)$ \\
\hline Did not answer & $2(2.9)$ \\
\hline \multicolumn{2}{|c|}{ In the last 3 months, have you recommended patients to use supplemental apps to their current psychotherapy plan? } \\
\hline Yes & $19(27.9)$ \\
\hline No & $48(70.6)$ \\
\hline Did not answer & $1(1.5)$ \\
\hline \multicolumn{2}{|c|}{ In the last 3 months, have you recommended online resources to patients? } \\
\hline Yes & $38(55.9)$ \\
\hline No & $27(39.7)$ \\
\hline Did not answer & $3(4.4)$ \\
\hline
\end{tabular}

Table 3. Perceived barriers by trainees.

\begin{tabular}{|c|c|c|c|c|c|c|c|c|}
\hline Question & Privacy & Safety & Liability & Cost & $\begin{array}{l}\text { Lack of evi- } \\
\text { dence }\end{array}$ & $\begin{array}{l}\text { Too much } \\
\text { data }\end{array}$ & $\begin{array}{l}\text { Lack of reim- } \\
\text { bursement }\end{array}$ & $\begin{array}{l}\text { Lack of clini- } \\
\text { cal guidance }\end{array}$ \\
\hline $\begin{array}{l}\text { What do you feel are the } \\
\text { greatest barriers for using } \\
\text { mobile devices in the care } \\
\text { of patients? (Select up to } \\
\text { three), n }(\%)\end{array}$ & $38(55.9)$ & $5(7.4)$ & $15(22)$ & $5(7.4)$ & $20(29.4)$ & 12 (17.6) & $11(16.2)$ & 27 (39.7) \\
\hline
\end{tabular}

\section{Discussion}

This multisite study provides the first results on both psychiatry trainee ownership and their use of mobile phones for clinical education and patient care. We found that all psychiatry residents who participated in this survey owned mobile phones, which exceeds the mobile phone usage in the general population.

Further, the selected programs cover multiple hospitals within their city and are exposed to various types of EMRs. Although psychiatry residents own mobile phones, their reported use in our survey suggests that it is limited. The most common reported clinical use is communicating with clinical staff, especially for scheduling, and the second most common use is to access patient information. Although these uses may seem simple in that mobile phones are being used for communication, each also 
raises educational opportunities for educators to consider. There have been recent efforts to ensure residents are educated about best practices with social media and websites such as Facebook, and in 2014, Dejong and Gorrindo [8] have discussed about texting and the professionalism principles when communicating with patients using this method. Among internal medicine residents, the use of short message service (SMS) texting as a means of communication has also raised the ethical question of whether the ease of use is a potential breach of patient privacy [9]. Overall, there remains a limited amount of literature on how we teach psychiatry residents best practices for using mobile devices in clinical care roles. If residents are using them primarily for scheduling purposes, it is not difficult to imagine that soon they will also be using mobile phones for direct clinical care roles as well - and indeed our survey suggests that some already are.

Several limitations of this study should be noted. All data were self-reported, and we did not verify through direct observation how residents are using mobile phones and apps in clinical care. Although our study is the first to examine this topic, our questions were not exhaustive and did not include details on app use when using with patients and communicating with other staff members. We attempted to collect demographic data including gender and age, but due to low compliance, the limited data gathered could not be analyzed. We also did not obtain details on how residents evaluate and consider whether to use or not use an app. We designed a quantitative design with yes/no questions to understand the basics of mobile device usage among trainees. Future iterations of our study with Likert scales and more qualitative metrics would be important to complete the understanding of mobile device use among trainees. Due to concerns of lack of participation, we also designed our survey with yes/no questions to help increase compliance. It is important to note that our study was limited to 2 sites, and it is difficult to assess how generalizable our results are outside of these 2 study sites.

Given this was a convenience sample and we have no information from the residents who did not choose to participate, it is, however, possible that the residents more interested in technology were more likely to participate. On the basis of our survey, future studies can consider larger trainee population of various specialties, while providing more flexibility in the survey including clarifying practice setting and providing more write in options. This can help provide further data and understanding on which areas of practice should be targeted through education as well as enhancing work flow using technology.

Despite a robust app development industry, clinical evidence for the effectiveness of apps in psychiatry remains nascent. Further, evaluating the safety and quality of apps is challenging. Thus, the fact that some residents are venturing into this largely unknown space of apps is notable. Generally, our survey suggests that trainees are at times hesitant in using mobile devices. However, a partial integration in their clinical practice is evident in that over $89 \%$ of trainees use their mobile devices to communicate with clinical staff. In addition, over 55\% report using desktop computers to communicate with their patients, and the authors expect trainees to transition to using mobile devices in their patient communication due to increased availability and convenience of mobile devices. This reflects the need for educators and supervisors to consider at least inquiring if residents are using these tools and to prepare our trainees to potentially utilize these tools in practice.

Table 4. Suggested curriculum - Technology in Psychiatry Seminar (TIPS).

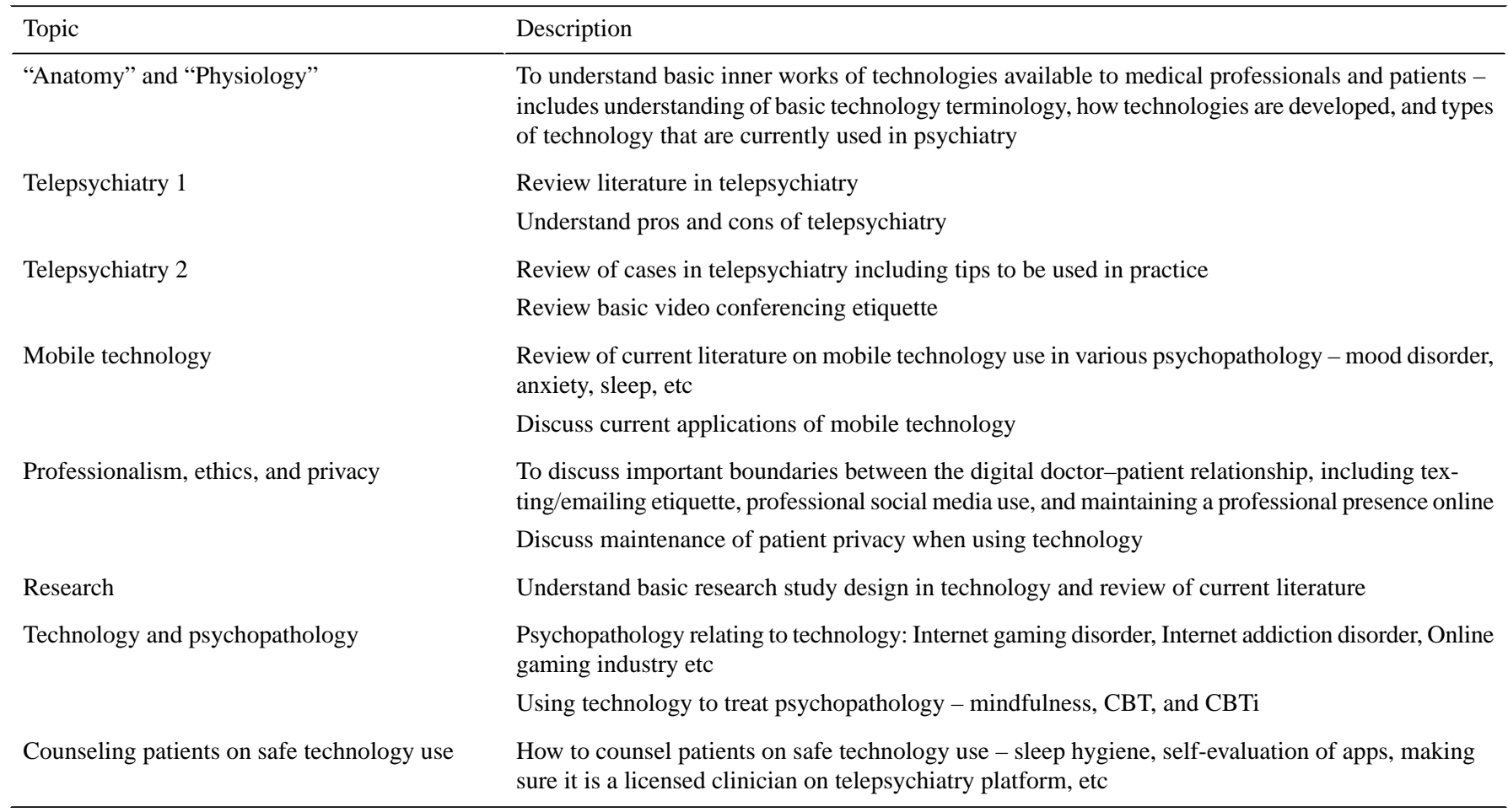

Along these lines, our survey results suggest several opportunities for psychiatric educators to offer guidance and support for trainees regarding the use of mobile technology. Residents raised several important concerns about apps including 
privacy, lack of clinical guidance, lack of evidence, and liability, among others. However, each of these topics represents a complex area as mobile technology for health care is advancing more rapidly than legislation, digital security, clinical trials, and clinical teaching can equal. Another challenge is that many educators may be less familiar or excited by mobile phone apps and other new technologies and thus lack the necessary experiences to educate residents. Given that "lack of clinical guidance" was selected as the number 2 barrier to using mobile technology in patient care, this suggests there is a need for a curriculum focused on digital and mobile technologies. Creating a curriculum in technology during graduate medical training could provide a platform for introducing trainees to basic concepts about current technologies including mobile technology and technology use in patient care [10]. In a technology curriculum, the core concept is not only to include basic concepts but also to provide principles for evaluating technology from a clinical perspective. Therefore, the authors propose the development of a technology curriculum that educates trainees in various digital psychiatry tools including EMR, telepsychiatry, mobile device use, and wearables. This potential technology curriculum is listed in Table 4 . Further research and experience would be needed to find the most effective curriculum. Fundamentally, having a technology curriculum can allow trainees to better understand technologies relating to patient care without over incorporation in daily practice.
From this study, trainees are interested in using and have used mobile technology in practice. However, their education on how to use it remains lacking, and educators should consider including mobile technology education as a part of the residents' curriculum. Encouraging mobile technology research is also important. Until further research is conducted and empirical data are collected, basic clinical pearls and core concepts for mobile technology such as understanding the clinical evidence and privacy regulations could be the foundation of a technology curriculum. Although research- and evidence-based use of mobile technology is still in development, educators can teach residents how to dissect an app beyond its appearance and usability. Currently, The American Psychiatric Association's App Evaluation Task Force Committee is trying to understand mobile technology and create guidelines for clinicians to better evaluate apps for themselves and for patients [11].

Psychiatry trainees use mobile phones for their work, mainly for scheduling and administrative tasks. Though they remain hesitant to incorporate mobile health into their direct clinical care, partial integration of a mobile device is evident. Part of the hesitance among trainees appears to be due to the lack of education and guidance during their current training. It is imperative to prepare trainees to practice in the 21 st century where mobile phone use is part of daily life so that they will be knowledgeable in helping patients understand potential impacts of mobile technology. Such preparation and training may require the development of a new curriculum and educational efforts.

\section{Conflicts of Interest}

None declared.

\section{References}

1. Pewinternet. 2017. Mobile Fact Sheet URL: http://www.pewinternet.org/fact-sheet/mobile/ [accessed 2017-09-20] [WebCite Cache ID 6tcdiS0hD]

2. Tran K, Morra D, Lo V, Quan SD, Abrams H, Wu RC. Medical students and personal smartphones in the clinical environment: the impact on confidentiality of personal health information and professionalism. J Med Internet Res 2014 May 22;16(5):e132 [FREE Full text] [doi: 10.2196/jmir.3138] [Medline: 24855046]

3. Snow C, Torous J, Gordon-Elliott J, Penzner J, Meyer F, Boland R. Use of electronic resources for psychiatry clerkship learning: a medical student survey. Acad Psychiatry 2016 Dec 19 Epub ahead of print(forthcoming). [doi: 10.1007/s40596-016-0647-3] [Medline: 27995539]

4. Perez S. TechCrunch. 2014 Aug 21. Majority Of Digital Media Consumption Now Takes Place In Mobile Apps URL: https://techcrunch.com/2014/08/21/majority-of-digital-media-consumption-now-takes-place-in-mobile-apps/ [accessed 2017-09-20] [WebCite Cache ID 6tce6vnPL]

5. Boruff J, Storie D. Mobile devices in medicine: a survey of how medical students, residents, and faculty use smartphones and other mobile devices to find information. J Med Libr Assoc 2014 Jan;102(1):22-30 [FREE Full text] [doi: 10.3163/1536-5050.102.1.006] [Medline: 24415916]

6. Gagnon MP, Ngangue P, Payne-Gagnon J, Desmartis M. m-Health adoption by healthcare professionals: a systematic review. J Am Med Inform Assoc 2016 Jan;23(1):212-220. [doi: 10.1093/jamia/ocv052] [Medline: 26078410]

7. Mobasheri M, King D, Johnston M, Gautama S, Purkayastha S, Darzi A. The ownership and clinical use of smartphones by doctors and nurses in the UK: a multicentre survey study. BMJ Innov 2015 Oct 07;1(4):174-181. [doi: 10.1136/bmjinnov-2015-000062]

8. DeJong S, Gorrindo T. To text or not to text: applying clinical and professionalism principles to decisions about text messaging with patients. J Am Acad Child Adolesc Psychiatry 2014 Jul;53(7):713-715. [doi: 10.1016/j.jaac.2014.05.002] [Medline: 24954818]

9. Prochaska M, Bird A, Chadaga A, Arora V. Resident use of text messaging for patient care: ease of use or breach of privacy? JMIR Med Inform 2015 Nov 26;3(4):e37 [FREE Full text] [doi: 10.2196/medinform.4797] [Medline: 26611620]

10. Gipson SYMT, Kim JW, Shin AL, Kitts R, Maneta E. Teaching child and adolescent psychiatry in the twenty-first century. Child Adolesc Psychiatr Clin N Am 2017 Jan;26(1):93-103. [doi: 10.1016/j.chc.2016.07.004] 
11. Torous J, Chan S, Gipson S. Psychnews. 2016 Jan 29. APA Task Force to Develop Guidelines to Assess Apps, Wearable Sensors URL: http://psychnews.psychiatryonline.org/doi/10.1176/appi.pn.2016.2a10 [accessed 2017-09-25] [WebCite Cache ID 6tk2izAWJ]
Abbreviations
CBT: Cognitive Behavioral Therapy
CBTi: Cognitive Behavioral Therapy for insomnia
EMRs: electronic medical records
SMS: electronic medical records
TIPS: Technology in Psychiatry Seminar

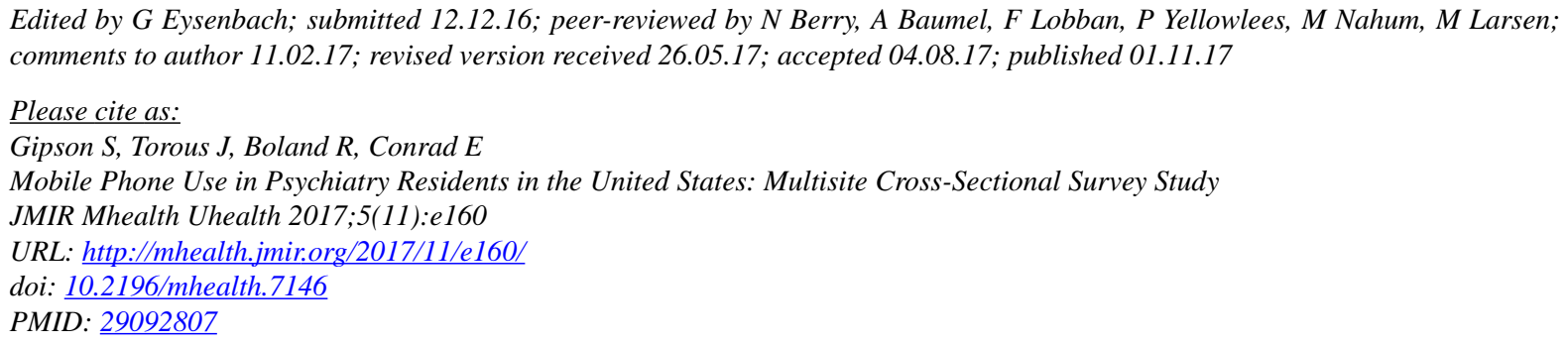

(C) Shih Gipson, John Torous, Robert Boland, Erich Conrad. Originally published in JMIR Mhealth and Uhealth (http://mhealth.jmir.org), 01.11.2017. This is an open-access article distributed under the terms of the Creative Commons Attribution License (https://creativecommons.org/licenses/by/4.0/), which permits unrestricted use, distribution, and reproduction in any medium, provided the original work, first published in JMIR mhealth and uhealth, is properly cited. The complete bibliographic information, a link to the original publication on http://mhealth.jmir.org/, as well as this copyright and license information must be included. 